\title{
Changes in hepatic glycogen cycling during a glucose load in healthy humans
}

Received: 13 May 2005 / Accepted: 19 September 2005 / Published online: 28 December 2005

(C) Springer-Verlag 2005

\begin{abstract}
Aims/hypothesis: Glycogen cycling, i.e. simultaneous glycogen synthesis and glycogenolysis, affects estimates of glucose fluxes using tracer techniques and may contribute to hyperglycaemia in diabetic conditions. This study presents a new method for quantifying hepatic glycogen cycling in the fed state. Glycogen is synthesised from glucose by the direct and indirect (gluconeogenic) pathways. Since glycogen is also synthesised from glycogen, i.e. glycogen $\rightarrow$ glucose 1-phosphate $\rightarrow$ glycogen, that synthesised through the direct and indirect pathways does not account for $100 \%$ of glycogen synthesis. The percentage contribution of glycogen cycling to glycogen synthesis then equals the difference between the sum of the percentage contributions of the direct and indirect pathways and 100. Materials and methods: The indirect and direct pathways were measured independently in nine healthy volunteers who had fasted overnight. They ingested ${ }^{2} \mathrm{H}_{2} \mathrm{O}(5 \mathrm{ml} / \mathrm{kg}$ body water $)$ and were infused with $\left[5-{ }^{3} \mathrm{H}\right]$ glucose and acetaminophen (paracetamol; $1 \mathrm{~g}$ ) during hyperglycaemic clamps $(7.8 \mathrm{mmol} / \mathrm{l})$ lasting $8 \mathrm{~h}$. The percentage contribution of the indirect pathway was calculated from the ratio of ${ }^{2} \mathrm{H}$ enrichments at carbon 5 to that at carbon 2 , and the contribution of the direct pathway was determined from the ${ }^{3} \mathrm{H}$-specific activity, relative to plasma
\end{abstract}

H. Stingl $\cdot$ A. Brehm $\cdot$ P. Nowotny $\cdot$ W. Waldhäusl $\cdot$ M. Roden Division of Endocrinology and Metabolism,

Department of Internal Medicine III,

Medical University of Vienna,

Vienna, Austria

V. Chandramouli - W. C. Schumann - B. R. Landau

Departments of Medicine and Biochemistry,

Case Western Reserve University,

Cleveland, $\mathrm{OH}, \mathrm{USA}$

M. Roden $(\bowtie)$

First Medical Department, Hanusch Hospital,

Heinrich Collin Strasse 30,

A-1140, Vienna, Austria

e-mail: michael.roden@meduniwien.ac.at

Tel.: +43-1-9102185011

Fax: +43-1-9102185019 glucose, of the urinary glucuronide excreted between 2 and 4, 4 and 6, and 6 and $8 \mathrm{~h}$. Results: Glucose infusion rates increased $(p<0.01)$ to $\sim 50 \mu \mathrm{mol} \mathrm{kg}^{-1} \mathrm{~min}^{-1}$. Plasma insulin and the insulin : glucagon ratio rose $\sim 3.6-$ and $\sim 8.3$-fold $(p<0.001)$, respectively. From the difference between $100 \%$ and the sum of the direct $(2-4 \mathrm{~h}, 54 \pm 6 \% ; 4-6 \mathrm{~h}, 59 \pm 5 \% ; 6-8 \mathrm{~h}$, $63 \pm 4 \%)$ and indirect $(32 \pm 3,38 \pm 4,36 \pm 3 \%)$ pathways, glycogen cycling was seen to be decreased $(p<0.05)$ from $14 \pm 4 \%(2-4 \mathrm{~h})$ to $4 \pm 3 \%(4-6 \mathrm{~h})$ and $1 \pm 3 \%(6-8 \mathrm{~h})$. Conclusions/interpretation: This method allows measurement of hepatic glycogen cycling in the fed state and demonstrates that glycogen cycling occurs most in the early hours after glucose loading subsequent to a fast.

Keywords Deuterated water - Gluconeogenesis · Glucose fluxes - Glycogenolysis · Hepatic glycogen cycling

Abbreviations DHAP: dihydroxyacetone 3-phosphate . F6P: fructose 6-phophate - GAP: glyceraldehyde 3-phosphate - G1P: glucose 1-phosphate - G6P: glucose 6-phosphate $\cdot$ MRS: magnetic resonance spectroscopy

\section{Introduction}

Simultaneous synthesis and breakdown of glycogen (glycogenolysis) is termed glycogen cycling [1]. Glycogen cycling could be an important factor in limiting the accumulation of liver glycogen and could thereby determine how fast a glucose load is taken up from the blood [2]. Increased glycogen cycling may help explain why glycogen content in type 2 diabetic patients is less than in healthy subjects [3] and could contribute to postprandial hyperglycaemia in the diabetic state $[2,4,5]$.

Gluconeogenesis is defined as the formation from noncarbohydrate precursors of glucose and glycogen $[6,7]$. Glycogen cycling has limited the interpretation of estimates of gluconeogenesis [2, 8], since its contribution cannot be excluded by current methods, e.g. using ${ }^{2} \mathrm{H}_{2} \mathrm{O}[9$, 
10] and magnetic resonance spectroscopy (MRS) [11]. Fluxes through the hepatic gluconeogenic pathway could also proceed directly to glycogen rather than into plasma glucose $[12,13]$. Hence, unless all the label cycled by isotope techniques through glycogen to glucose were measured, the immediate input from gluconeogenesis into plasma glucose would underestimate total flux through the gluconeogenic pathway, i.e. a portion would be deposited in liver glycogen [14]. This could have particular relevance for certain metabolic conditions, e.g. during a glucose load or in type 2 diabetes [4]. Interestingly, the ${ }^{2} \mathrm{H}_{2} \mathrm{O}$ and MRS methods yield similar results in healthy humans during fasting [15-17] but different results in patients with liver cirrhosis [18] and type 2 diabetes [4], and during NEFA elevation $[16,17,19]$, supporting the idea that glycogen cycling operates differently in diabetes mellitus and certain nutritive conditions.

Hepatic glycogen is synthesised from glucose 6-phosphate (G6P) by two pathways [20] (Fig. 1): the direct pathway [21], by which glucose is converted into the glycosyl units of the glycogen with its carbon skeleton remaining intact; and the indirect pathway, by which, via the gluconeogenic pathway [22], the glucose is first cleaved to three carbon-containing compounds that are precursors of the glycosyl units [23]. During subsequent fasting, glucose is released by glycogenolysis from the liver into the circulation.

The percentage contribution of the direct pathway to glycogen synthesis can be estimated from the ratio of label in the glycogen to that in the glucose when the glucose is labelled, since this label is removed in the indirect but not in the direct pathway, e.g. from $\left[5-{ }^{3} \mathrm{H}\right]$ glucose. When ${ }^{2} \mathrm{H}_{2} \mathrm{O}$ is administered ${ }^{2} \mathrm{H}$ will be bound to carbons 2 and 5 of the glycosyl units formed by the indirect pathway and only to carbon 2 via the direct pathway [10]. The percentage contribution of the indirect pathway can then be estimated from the ratio of the ${ }^{2} \mathrm{H}$ enrichment of the hydrogen bound to carbon 5 to that of the hydrogen bound to carbon 2 of the glycosyl units, glucose from the acetaminophen (paracetamol) glucuronide then being used to sample the hepatic UDP glucose pool from which these glycosyl units are formed $[24,25]$.
Fig. 1 Pathways of liver glycogen synthesis and breakdown. Glycogen synthesis may occur directly (direct pathway) or by the detour of the gluconeogenic pathway (indirect pathway). During subsequent fasting, glucose is released by the liver into circulation (glycogenolysis)

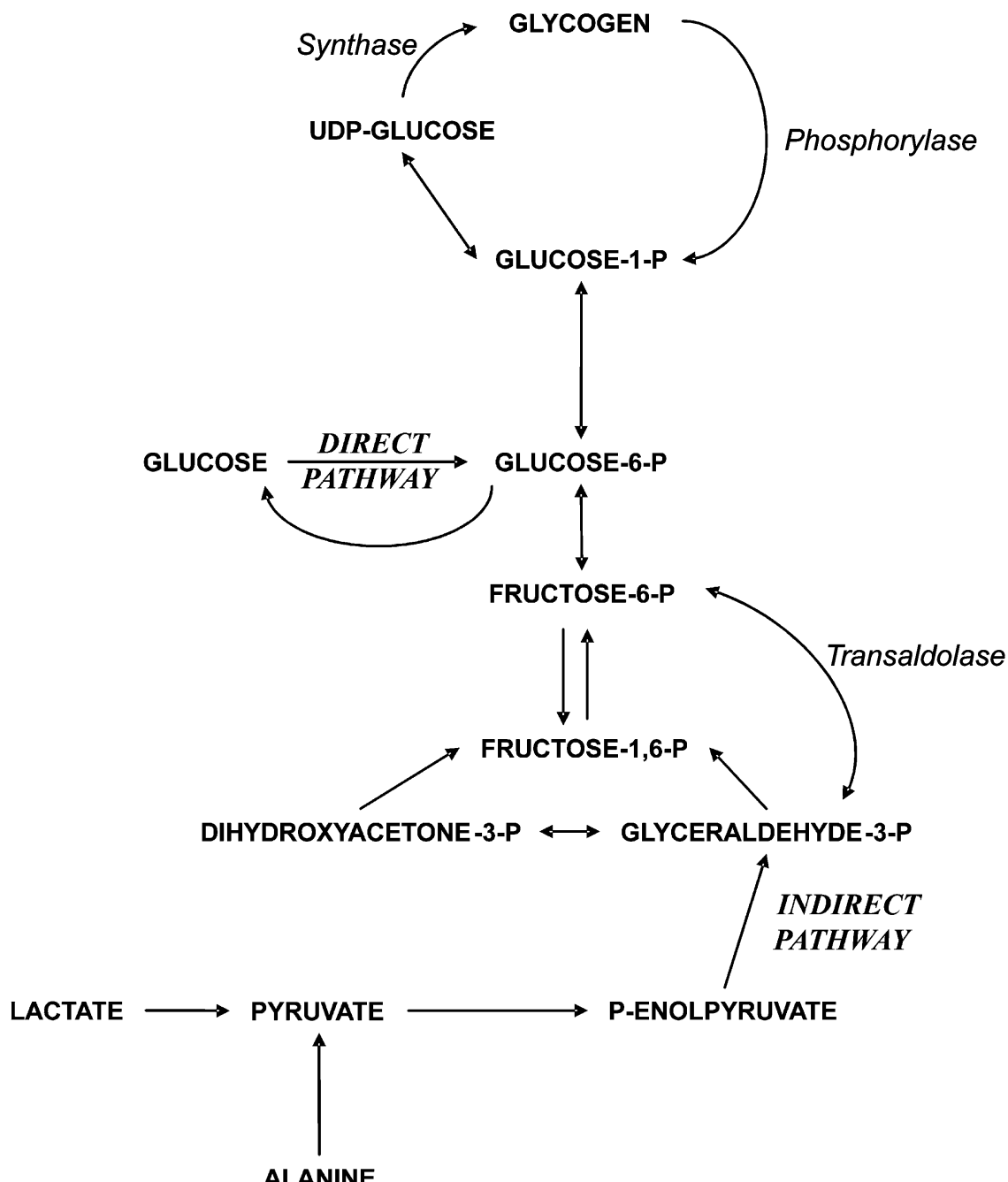

ALANINE 
The rationale we have now used to estimate the extent of glycogen cycling contributions over several hours, in normal subjects infused with glucose to maintain a concentration of $\sim 7.8 \mathrm{mmol} / \mathrm{l}$ after fasting overnight, is as follows. Unless there is glycogen cycling, the sum of the percentage contributions of the direct and indirect pathways to hepatic glycogen synthesis should equal $100 \%$. The direct pathway is measured with $\left[5-{ }^{3} \mathrm{H}\right]$ glucose and the indirect pathway is measured by using ${ }^{2} \mathrm{H}_{2} \mathrm{O}$ and acetaminophen to sample the hepatic UDP glucose pool. The sum will be less than $100 \%$ of glycogen cycling, since glycogen is then synthesised from the glucose 1-phosphate (G1P) formed in glycogen breakdown. This assumes the hydrogen bound to carbon 2 of the G1P is enriched in ${ }^{2} \mathrm{H}$ from ${ }^{2} \mathrm{H}_{2} \mathrm{O}$ during synthesis.

\section{Subjects and methods}

\section{Protocol}

Nine male healthy volunteers (age range 23-29 years; BMI $24.1 \pm 0.8 \mathrm{~kg} / \mathrm{m}^{2}$ ) without a family history of diabetes or evidence of any other disease ate an isocaloric diet $(>50 \%$ carbohydrates per day) and refrained from physical exercise for at least 3 days. All participants gave informed written consent to the protocol, which was approved by our institutional ethics board. They ingested a liquid meal (60\% carbohydrate, $20 \%$ protein, $20 \%$ fat) at 18.30 hours [26] and fasted overnight.

At 08.00 hours, $96.2 \mathrm{kBq}$ of $\left[5-{ }^{3} \mathrm{H}\right]$ glucose was given as a bolus in $1 \mathrm{ml}$ of isotonic saline. For the next $8 \mathrm{~h}$, plasma glucose was maintained at $7.8 \mathrm{mmol} / \mathrm{l}$ by employing a variable infusion of $20 \%$ glucose labelled with $\left[5-{ }^{3} \mathrm{H}\right]$ glucose $(7.03 \mathrm{kBq} / \mathrm{g})$ to assess the contribution of the direct pathway to glycogen formation and endogenous glucose production $[27,28]$. At 08.00 hours subjects started to drink a total of $5 \mathrm{ml}$ of ${ }^{2} \mathrm{H}_{2} \mathrm{O}(99.9 \%$ enriched; Cambridge Isotope Laboratories, Andover, MA, USA) per kg body water, divided into four equal doses spaced at intervals of 30 min each [10], in order to assess the contribution of the indirect pathway to glycogen formation. Body water was estimated at $60 \%$ of body weight [9]. Thereafter, subjects were asked to drink a minimum of one glass of $0.5 \%{ }^{2} \mathrm{H}_{2} \mathrm{O}$ enriched water per hour to maintain isotopic equilibrium in body water. To determine labelled urinary glucuronide, $1 \mathrm{~g}$ acetaminophen (Pro-Dafalgan, Upsa, France) was infused continuously from 09.00 until 15.00 hours.

During the study, blood samples were drawn every $5 \mathrm{~min}$ to monitor plasma glucose concentration and at defined time points for measurement of glucoregulatory hormones, ${ }^{2} \mathrm{H}$ enrichments and ${ }^{3} \mathrm{H}$-specific activities in glucose. Blood samples were chilled and centrifuged and supernatants were stored at $-20^{\circ} \mathrm{C}$. Urine was collected from 0 to $2 \mathrm{~h}$, from 2 to $4 \mathrm{~h}$, from 4 to $6 \mathrm{~h}$ and from 6 to $8 \mathrm{~h}$. To maintain the stability of glucuronide, $1 \mathrm{~N} \mathrm{HCl}$ was added in drops to the urine to adjust the $\mathrm{pH}$ to $\sim 4.5$; thereafter the urine was stored at $-20^{\circ} \mathrm{C}$.

\section{Analyses}

Hormones and metabolites Plasma glucose concentrations were measured with the glucose oxidase method (Glucose Analyzer II; Beckman Instruments, Fullerton, CA, USA; YSI 2300; Yellow Springs Instruments, Yellow Springs, OH, USA). Plasma concentrations of NEFA were determined by enzymatic methods (Wako Chemicals, Neuss, Germany; intra- and inter-assay CV 4.3 and $5.7 \%$, respectively). Plasma insulin ( $\mathrm{CV}<8 \%$ ), C-peptide $(\mathrm{CV}<9 \%)$ and glucagon $(\mathrm{CV}<8 \%)$ were measured by RIA (insulin, PharmaciaUpjohn, Uppsala, Sweden; C-peptide, CIS, Gif-SurYvette, France; glucagon, ICN Biomedicals, Costa Mesa, CA, USA).

Specific activities in plasma glucose To measure ${ }^{3} \mathrm{H}$ glucose-specific activity, the blood samples were diluted with water and deproteinised by adding equal volumes of $0.3 \mathrm{~N} \mathrm{Ba}(\mathrm{OH})_{2}$ and $0.3 \mathrm{~N} \mathrm{ZnSO}_{4}[9,29]$. The supernatant was deionised by passage through a column of AG1-X8 (Bio-Rad Laboratories, Hercules, CA, USA) in the formate form layered over AG50W-X8 (Bio-Rad) in the hydrogen form. The effluent was evaporated and glucose in the residue purified using an HPLC system (Waters, Milford, MA, USA) fitted with an HPX-87P column (Bio$\mathrm{Rad}$ ) with water at $80^{\circ} \mathrm{C}$ as solvent and at a flow rate of $0.5 \mathrm{ml} / \mathrm{min}$. Glucose eluted at $15-17 \mathrm{~min}$. This fraction was evaporated to dryness and the residue dissolved in $2 \mathrm{ml}$ of water. Duplicate aliquots were counted for ${ }^{3} \mathrm{H}$ activity $(\mathrm{dpm} / \mathrm{ml})$ in a liquid scintillation counter (Model 1600TR; Packard Instruments, Meriden, CT, USA) to a probable error of less than $1 \%$. The concentration of glucose $(\mathrm{mg} / \mathrm{ml})$ in aliquots, again in duplicate, was determined. Specific activity was then calculated by dividing $\mathrm{dpm} / \mathrm{ml}$ by $\mathrm{mg} / \mathrm{ml}$.

${ }^{2} \mathrm{H}$ enrichment in body water Enrichment in body water, measured as that in plasma water, was determined as described [30]. An aliquot of $50 \mu$ plasma was spiked with $0.2 \mu \mathrm{l}$ of acetone in $3.8 \mu \mathrm{l}$ of acetonitrile and $2 \mu \mathrm{l}$ of $10 \mathrm{~N} \mathrm{NaOH}$. After $24 \mathrm{~h}$ to allow exchange between the hydrogens of water and the acetone, the acetone was extracted into chloroform and assayed for ${ }^{2} \mathrm{H}$ enrichment by GC-MS on a Hewlett Packard 6890 series gas chromatograph interfaced to a Hewlett Packard 5973 Mass Selective Detector (Agilent Technologies, Palo Alto, CA, USA). Assays of water samples with enrichment from 0 to $1 \%$ provided the calibration curve. Plasma was collected from $2 \mathrm{ml}$ blood samples in tubes containing EDTA. Corrections were made for dilution of water in the blood [31] by the water in which the EDTA was dissolved. 
Specific activities and ${ }^{2} \mathrm{H}$ enrichments in urinary glucuronide $[25,32]$

The amount of glucuronide was determined in each 2-h collection [33, 34]. The least amounts were in urine collected from 10.00 hours to noon, usually about one-third to one-half that in the other urine samples. Each urine sample was taken to $\mathrm{pH} 9$ with $10 \mathrm{~N} \mathrm{NaOH}$ and applied to an ion exchange column (AG1-X8; Bio-Rad) in its acetate form. The column was washed with water and then increasing concentrations of acetic acid to $5 \mathrm{~mol} / \mathrm{l}$. The fractions in which the glucuronide eluted were identified using carbazole [35]. Most glucuronide eluted in the $5 \mathrm{~mol} / \mathrm{l}$ fraction. The fractions containing glucuronide were combined and evaporated to dryness. The residue was dissolved in a minimum amount of methanol and the glucuronide reduced to its glucoside by addition of diborane. After destroying excess diborane, the glucoside was hydrolysed with $\beta$-glucosidase. $\mathrm{Ba}(\mathrm{OH})_{2}$ and $\mathrm{ZnSO}_{4}$ were then added to the reaction mixture and the supernatant was deionised by passage through the anion and cation exchange resins as in the isolation of glucose from blood. The effluent was evaporated to dryness. The glucose was isolated from the residue by preparative paper chromatography using a butanol-acetic acid-water system (4:1:5 by volume) [36]. Guide spots of glucose were used to identify the portion of the paper containing the glucose. The glucose was eluted from the paper and purified in the HPLC system with the HPX-87P column and water as solvent. The specific activity of the glucose collected from the column was determined as for glucose from blood, i.e. $\mathrm{dpm} / \mathrm{ml}$ was determined in an aliquot and glucose concentration in another aliquot. The glucose was subjected to repeated passage through the HPLC system until a constant ${ }^{3} \mathrm{H}$ specific activity was achieved.

After the glucose had been purified to constant specific activity, the ${ }^{2} \mathrm{H}$ enrichments in the hydrogens bound to carbons 2 and 5 of the glucose were determined. A portion of the glucose was enzymatically converted to ribulose 5phosphate, which was reduced with sodium borohydride to a mixture of arabitol 5-phosphate and ribitol 5-phosphate [10]. These were oxidised with periodate to yield formaldehyde containing carbon 2 with its hydrogen. Another portion of the glucose was converted to xylose which was oxidised with periodate to yield formaldehyde containing carbon 5 with its hydrogen [10,37]. The formaldehydes were condensed with ammonia to form hexamethylenetetramines, which were assayed for ${ }^{2} \mathrm{H}$ enrichment in the GCMS system. The hexamethylenetetramines prepared by periodate oxidation of $\left[5-{ }^{3} \mathrm{H}\right]$ sorbitols of known enrichments served as standards.

\section{Calculations and statistical evaluation}

Whole-body glucose disposal was calculated from mean glucose infusion rates for 20-min intervals. Rates of endogenous glucose production during the hyperglycaemic clamp were calculated by using the Steele equations for non-steady-state conditions [38].

The percentage contribution of the direct pathway to glycogen formation was calculated by dividing the ${ }^{3} \mathrm{H}-$ specific activity of glucose in the glucuronide from the urine collected from 10.00 hours to noon by the average of the ${ }^{3} \mathrm{H}$-specific activity in blood glucose from blood collected at 9.00, 10.00 and 11.00 hours and multiplying by 100 [39]. The ${ }^{3} \mathrm{H}$-specific activities in the glucose from glucuronide in the urines collected from noon to 14.00 hours and from 14.00 to 16.00 hours were divided by the average of the ${ }^{3} \mathrm{H}$-specific activities in glucose from bloods collected during those times.

The percentage contribution of the indirect pathway to glycogen formation in these three periods was calculated by multiplying by 100 the ratio of ${ }^{2} \mathrm{H}$ enrichment of the hydrogen bound to carbon 5 to that bound to carbon 2 of the glucoses from the glucuronides.
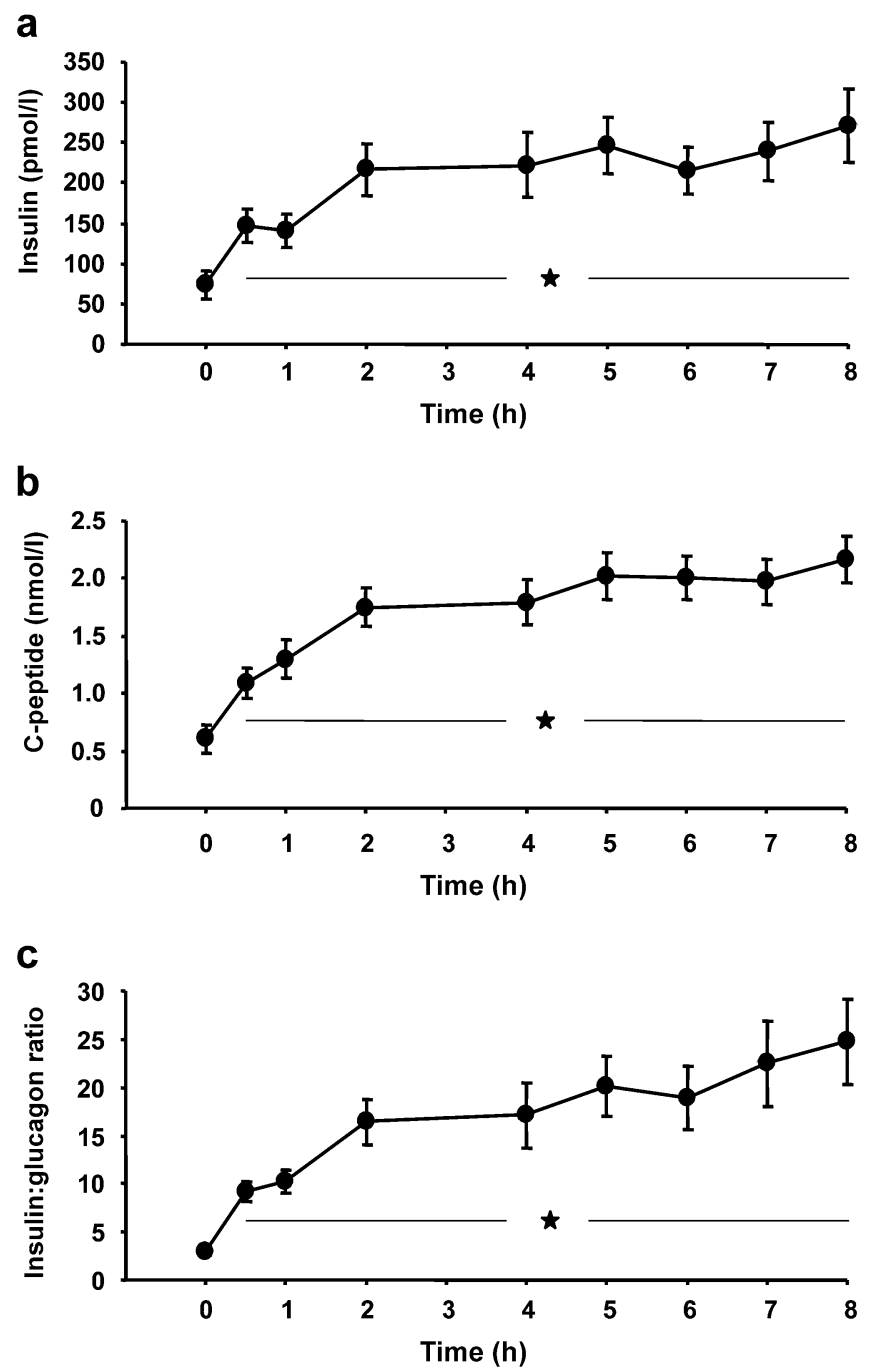

Fig. 2 a-c Plasma insulin and C-peptide concentrations, and molar insulin : glucagon ratios during hyperglycaemic clamp conditions in healthy volunteers $(n=9) .{ }^{*} p<0.0001$ vs basal 
The percentage contribution of glycogen cycling to glycogen formation was set equal to $100 \%$ minus the percentage contributions of the direct and indirect pathways.

The ${ }^{2} \mathrm{H}$ enrichment of the hydrogen bound to carbon 2 of the glucose from the glucuronide in each of the three urine collections was divided by the average of the ${ }^{2} \mathrm{H}$ enrichments in plasma water determined at hourly intervals over the time of the urine collection, giving carbon $2:{ }^{2} \mathrm{H}_{2} \mathrm{O}$ ratios.

Data are presented as mean \pm SEM. Student's $t$-test and repeated-measurements ANOVA were used for statistical comparisons within the time courses of the experiments. A $p$ level $\leq 0.05$ was taken to indicate statistical significance. Statistical calculations were done using the SigmaStat software package (Jandel Corporation, San Rafael, CA, USA).
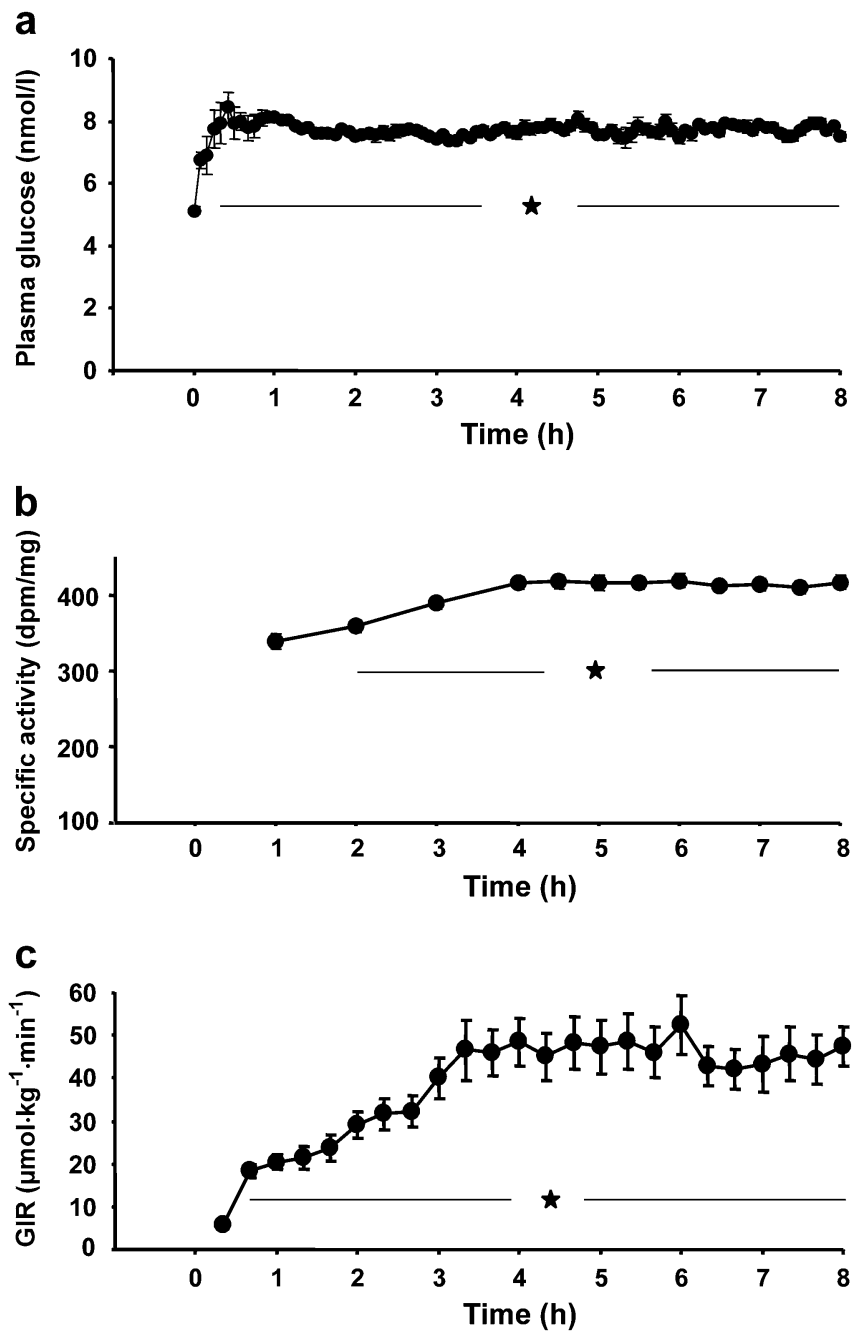

Fig. 3 a-c Plasma glucose concentration, specific activity and glucose infusion rate (GIR) during hyperglycaemic clamp in healthy volunteers $(n=9)$. ${ }^{*} p<0.0001$ vs basal

\section{Results}

During the hyperglycaemic clamp, plasma insulin and C-peptide concentrations increased to reach $\sim 3.6$-fold $(p<0.001)$ above baseline at the end of the study (Fig. 2). Plasma glucagon concentrations decreased $(p<0.005)$ from $23 \pm 2$ to $16 \pm 2 \mathrm{pmol} / 1$ within $30 \mathrm{~min}$, thereafter declining slightly to $11 \pm 1 \mathrm{pmol} / 1$ by the end of the study $(p<0.005)$. The molar insulin : glucagon ratio was $3.0 \pm 0.5$ at baseline and increased $\sim 8.3$-fold $(p<0.001)$ (Fig. 2).

Plasma glucose was clamped at $7.77 \pm 0.01 \mathrm{mmol} / 1$ for 8 h (Fig. 3). Glucose infusion rates increased $(p<0.0001)$ during the first $3 \mathrm{~h}$ of the clamp and then remained constant (Fig. 3). Plasma NEFA concentrations were $421 \pm 108 \mu \mathrm{mol} / 1$ at baseline and decreased rapidly to $\sim 30 \mu \mathrm{mol} / 1$ during hyperglycaemia $(p<0.0001)$.

Plasma water ${ }^{2} \mathrm{H}$ enrichments were $0.53 \pm 0.03 \%$ at $2 \mathrm{~h}$; between 4 and $8 \mathrm{~h}$ they were $0.55 \pm 0.02 \%$ without any change during this period. During the first $3 \mathrm{~h}$ of the study, ${ }^{3} \mathrm{H}$-specific activity increased $(p<0.001)$ from $337 \pm 10(1 \mathrm{~h})$ to $388 \pm 9 \mathrm{dpm} / \mathrm{mg}(3 \mathrm{~h})$ and $419 \pm 8 \mathrm{dpm} / \mathrm{mg}(4 \mathrm{~h})$, thereafter being constant until $8 \mathrm{~h}(415 \pm 8 \mathrm{dpm} / \mathrm{mg})$ (Fig. 3). Specific activity of the infusate was $397 \pm 13 \mathrm{dpm} / \mathrm{mg}$.

Endogenous glucose production was $1.4 \pm 0.5 \mu \mathrm{mol} \mathrm{kg}-1$ $\min ^{-1}$ at $2 \mathrm{~h}$ and was completely suppressed within $\sim 3 \mathrm{~h}$ during hyperglycaemia and subsequent hyperinsulinaemia $\left(\sim-0.9 \mu \mathrm{mol} \mathrm{kg}{ }^{-1} \mathrm{~min}^{-1}\right)$.

Unfortunately, in two subjects too little glucuronide was excreted to yield an adequate amount of glucose from 2 to $4 \mathrm{~h}$, and in one of them also from 4 to $6 \mathrm{~h}$. Therefore, data on the pathways of glycogen synthesis are presented with $n=7$ for $2-4 \mathrm{~h}$ and $n=8$ for $4-6 \mathrm{~h}$. The contribution of the direct pathway to glycogen synthesis was $54 \pm 6 \%(2-4 \mathrm{~h})$, $59 \pm 5 \%(4-6 \mathrm{~h})$ and $63 \pm 4 \%(6-8 \mathrm{~h})$. The contribution of the indirect pathway to glycogen synthesis was $32 \pm 3 \%$ $(2-4 \mathrm{~h}), 38 \pm 4 \%$ (4-6 h, $p<0.05$ vs basal) and $36 \pm 3 \%$ (6-8 $\mathrm{h}, p<0.05$ vs basal). From the difference between $100 \%$ and the sum of the direct and indirect pathways, glycogen cycling decreased $(p<0.05)$ from $14 \pm 4 \%(2-4 \mathrm{~h})$ to $4 \pm 3 \%(4-6 \mathrm{~h})$ and $1 \pm 3 \%(6-8 \mathrm{~h})$ (Fig. 4$)$.

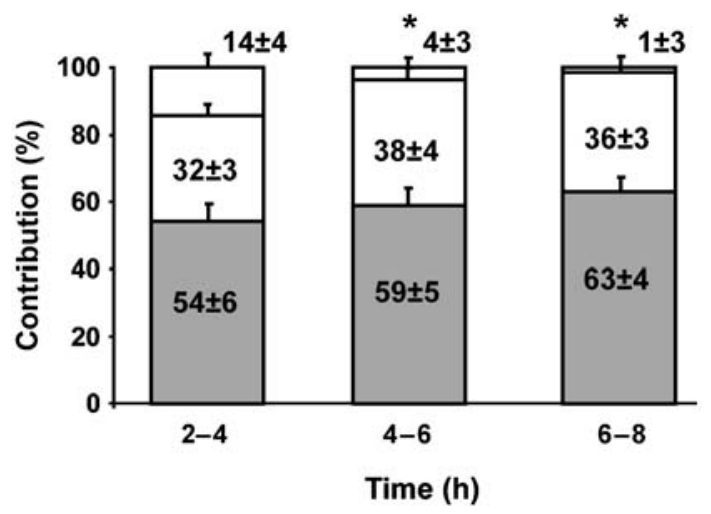

Fig. 4 Contributions of the direct (dark shading) and indirect (light shading) pathways and glycogen cycling (no shading) to hepatic glycogen synthesis at $2-4,4-6$ and $6-8 \mathrm{~h}$ of hyperglycaemic clamp in healthy volunteers $(n=9)$. ${ }^{*} p<0.0001$ vs $2-4 \mathrm{~h}$ 
The ratio of the enrichment at carbon 2 of glucose from the glucuronide to that in plasma water at $2-4 \mathrm{~h}$ was $0.83 \pm$ $0.12,0.84 \pm 0.10$ at $4-6$ and $0.82 \pm 0.09$ at $6-8 \mathrm{~h}$.

\section{Discussion}

In this study, the ingestion of ${ }^{2} \mathrm{H}_{2} \mathrm{O}$ was used to determine the indirect pathway of glycogen synthesis. The direct and indirect pathways of glycogen synthesis were assessed simultaneously. By subtracting the sum of the pathways from $100 \%$, an estimate of the extent of hepatic glycogen cycling was possible.

In a number of studies, estimates of the contributions of the direct and indirect pathways to glycogen formation have been made by calculating the contribution of either pathway, usually the direct pathway, and assuming the sum of their contributions is $100 \%$ [20,40]. This is so if there is no formation of glycogen from glycogen (the glycogen cycling pathway). Giving a glucose load after an overnight fast, the sum of the direct and indirect pathway contributions was $\sim 100 \%$ for $4-8 \mathrm{~h}$ in our study (Fig. 3). The sum was $14 \pm 4 \%$ less at $2-4 \mathrm{~h}$, indicating a small but significant contribution of glycogen cycling to glycogen formation in the early hours after beginning administration of the glucose load. The mean contribution of the direct pathway of $54 \%$ at $2-4 \mathrm{~h}$, rising to $63 \%$ at $6-8 \mathrm{~h}$, is in accordance with an estimate of the contribution of the direct pathway of about $50 \%$ in normal subjects after an overnight fast and about $70 \% 4 \mathrm{~h}$ after breakfast $[20,41]$. In addition, our results confirm previous studies in which the direct pathway accounted for $\sim 63 \%$ of glycogen formation after a glucose load [42].

After a glucose load, it presumably takes time for the body to change from the fasting to the feeding mode. This adaptation to the fed state is probably found in the increase in the contribution of the direct pathway relative to the indirect pathway of glycogen formation as meals progress (the switch from the gluconeogenic pathway in the fasted state). It can also be found perhaps in the presence of glucose cycling in the first few hours after a glucose load [43].

There are two possible explanations for the decline in the contribution of cycling with time. Either the factors determining flux through the cycle changed or the glycosyl units released were increasingly labelled. The increase in portal insulin relative to glucagon activities $[44,45]$ would favour an increase in glycogen synthesis and a decrease in the activity of phosphorylase, hence the breakdown of glycogen [46-48]. The glycosyl units deposited are assumed not to be those released [1]. If [5- $\left.{ }^{3} \mathrm{H}\right]$ glycosyl units formed from the $\left[5-{ }^{3} \mathrm{H}\right]$ glucose were those converted to G1P and hence glycogen, that cycling would go unrecognised and cycling would be underestimated. Evidence that the principle of last deposited-first removed is not absolute is provided by the finding that when ${ }^{13} \mathrm{C}$-labelled glycosyl units were deposited in glycogen and the deposition was continued by infusing unlabelled glucose, the amount of ${ }^{13} \mathrm{C}$ deposited in glycogen declined [2].

Several methods have been introduced for quantifying hepatic glycogen cycling in humans. All rely for their validity on the correctness of the assumptions that are made [1]. Glycogen cycling has been estimated to be small or absent in normal subjects fasted overnight $[1,4,15,18]$. On infusing glucose to maintain a concentration of $\sim 9.5 \mathrm{mmol} / \mathrm{l}$ in normal subjects who had fasted overnight, the rate of glycogen breakdown was estimated to be $31 \%$ of the rate of synthesis [2]. This estimate was made by labelling the glucose infused with ${ }^{13} \mathrm{C}$ and following the rates of appearance and disappearance of the ${ }^{13} \mathrm{C}$ from hepatic glycogen, measured using MRS. Petersen et al. [15] have examined the mechanism by which glucose and insulin inhibit net glycogenolysis in humans using a pulse-chase method to estimate glycogen synthesis and breakdown in subjects with glucose concentrations clamped at $5 \mathrm{mmol} / \mathrm{l}$. They did not detect any significant glycogen turnover in normal subjects fasted overnight. In fasted healthy humans, glycogen cycling was estimated to be only 5\% upon administering glucose to a concentration of $\sim 7.8 \mathrm{mmol} / 1$ [24]. This estimate was made from the ratio of ${ }^{3} \mathrm{H}:{ }^{14} \mathrm{C}$ activities in glucose formed from glucuronic acid conjugated to acetaminophen on administration of acetaminophen and trace $\left[2-{ }^{3} \mathrm{H}, 6-{ }^{14} \mathrm{C}\right]$ galactose. Using MRS, only the amount of G1P formed from glycogen that is not cycled to reform glycogen is included in the estimate of glycogen breakdown. Using the glucuronide, only the $\left[2-{ }^{3} \mathrm{H}, 6-{ }^{14} \mathrm{C}\right]$ G1P formed from the galactose that is cycled to UDP glucose and loses its ${ }^{3} \mathrm{H}$ bound to carbon 2 in the process is measured.

In our study, the assumptions made in estimating the contribution of gluconeogenesis to glycogen formation using ${ }^{2} \mathrm{H}_{2} \mathrm{O}$, i.e. the contribution of the indirect pathway, are analogous to those made in estimating the contribution of gluconeogenesis to glucose production [10]. ${ }^{2} \mathrm{H}$ is bound to carbons 5 and 2 of every glycosyl unit of glycogen formed via gluconeogenesis.

Binding at carbon 5 occurs in the hydration of phosphoenolpyruvate, e.g. from lactate and alanine, and in the isomerization between glyceraldehyde 3-P (G3P) and dihydroxyacetone 3-phosphate (DHAP), including DHAP from glycerol. Binding at carbon 2 occurs in the isomerization of fructose 6-phosphate (F6P) to G6P. ${ }^{2} \mathrm{H}$ is bound to carbon 2 of every glycosyl unit formed via the direct pathway. This occurs in the isomerisation of G6P from the glucose with F6P before its conversion to glycogen [49]. Via glycogen cycling, ${ }^{2} \mathrm{H}$ is bound to carbon 2 of G1P, formed by phosphorolysis of glycogen, before its reconversion to glycogen. This occurs in the equilibration of G1P with F6P, i.e. G1P $\rightarrow \mathrm{G} 6 \mathrm{P} \rightarrow \mathrm{F} 6 \mathrm{P} \rightarrow \mathrm{G} 6 \mathrm{P} \rightarrow \mathrm{G} 1 \mathrm{P}$. Rapid equilibration of G1P with G6P and of G6P with F6P is assumed because of relatively high activities of hepatic phosphoglucoisomerase and phosphoglucomutase $[50,51]$. 
Rapid equilibration of G6P with F6P is evident from a ratio of ${ }^{2} \mathrm{H}$ enrichment at carbon 2 of glucose to that in plasma water of $\sim 1.0$ when ${ }^{2} \mathrm{H}_{2} \mathrm{O}$ is ingested in the fasted state [5, $10,24]$. Rates of interconversion of G1P with G6P have been estimated to be at least ten-fold higher than other rates of glycogen formation and breakdown [52]. We do not know why the mean ratios of ${ }^{2} \mathrm{H}$ enrichment at carbon 2 to that in plasma water in the present study were only 0.82 0.84 . In our study, we used ${ }^{2} \mathrm{H}$ enrichment at carbon 2 of glucose from the urine glucuronide, and variation was greater than we have seen in the past. Because of the relatively large quantities of glucose converted to G6P and to G1P, equilibration with ${ }^{2} \mathrm{H}_{2} \mathrm{O}$ may have been incomplete and could have contributed to the ratio of $\sim 0.83$. The mean ratio was the same for all three collections, indicating that steady state was achieved.

The plasma glucose concentration of $\sim 7.8 \mathrm{mmol} / \mathrm{l}$ was reached within the first half-hour of infusion and was then maintained. The ${ }^{3} \mathrm{H}$-specific activity of glucose in plasma reached steady state by the 3rd to 4th hour, indicating the time needed for complete suppression of endogenous glucose production. Urinary acetaminophen glucuronic acid represents recently conjugated acetaminophen glucuronide, and the glucuronide component reflects its intrahepatic specific activity some $30-60$ min before voiding urine [39]. Therefore, since the infusion of acetaminophen was begun at 09.00 hours, a portion of the glucuronide excreted in the 2-4 h collection, i.e. between 10.00 hours and noon, was made before 10.00 hours. This is the reason for using the mean of the plasma glucose specific activities from 09.00 to 11.00 hours in estimating the direct pathway contribution for that collection. The last dose of ${ }^{2} \mathrm{H}_{2} \mathrm{O}$ was ingested at 09.30 hours, but the contribution of the indirect pathway is determined by the $5 / 2$ ratio and not the enrichment in water [53]. In our opinion, this calculation, if anything, underestimates the contribution of glycogen cycling in this early period. More glucuronide was presumably collected in the 11-12 $\mathrm{h}$ than in the 10-11 h period, since we know the amount of glucuronide excreted increased with time. More than half of the glucuronide in the 2-4 h collection was made after 10.00 hours and was therefore made when the specific activity of the glucose in blood was higher than that used in the calculation. Since the direct contribution equals the specific activity of the glucuronide divided by the specific activity of the glucose from which it was made, use of a lower glucose-specific activity in the calculation than that which actually existed could lead to overestimation of the percentage contribution of the direct pathway. To this extent, the contribution of the cycling could be underestimated.

Transaldolase catalyses the exchange reaction $\mathrm{F} 6 \mathrm{P}+$ $\mathrm{GAP} \leftrightarrow \mathrm{F} 6 \mathrm{P}+\mathrm{GAP}$, i.e. the top three carbons of F6P are transferred intact to glyceraldehyde 3-phosphate (GAP) [54]. There is evidence for the exchange occurring in several tissues [55]. $\left[2-{ }^{2} \mathrm{H}-\mathrm{GAP}\right]$ is formed in the isomerization of DHAP with GAP in the presence of the ${ }^{2} \mathrm{H}_{2} \mathrm{O}$. Via this exchange, F6P formed from G6P in the direct pathway would then be converted to $\left[5{ }^{2} \mathrm{H}\right] \mathrm{F} 6 \mathrm{P}$, i.e. glucose $\rightarrow \mathrm{G} 6 \mathrm{P} \rightarrow \mathrm{F} 6 \mathrm{P}+\left[2{ }^{2} \mathrm{H}\right] \mathrm{GAP} \leftrightarrow\left[5-{ }^{2} \mathrm{H}\right] \mathrm{F} 6 \mathrm{P}+\mathrm{GAP}$. The GAP would be converted to $\left[2-{ }^{2} \mathrm{H}\right] \mathrm{GAP}$ in the presence of the ${ }^{2} \mathrm{H}_{2} \mathrm{O}$. The pathway $\left[5-{ }^{3} \mathrm{H}\right] \mathrm{F} 6 \mathrm{P} \rightarrow\left[2,5-{ }^{2} \mathrm{H}\right] \mathrm{G} 6 \mathrm{P} \rightarrow$ glycogen would then be included in the estimate of the indirect rather than direct pathway contribution. $\left[5-{ }^{3} \mathrm{H}\right]$ Glucose was used to estimate the direct pathway's contribution in order to take into account this possible overestimation of the indirect pathway's contribution. Via the exchange, $\left[5-{ }^{3} \mathrm{H}\right]$ F6P formed from $\left[5-{ }^{3} \mathrm{H}\right] \mathrm{G} 6 \mathrm{P}$ in the direct pathway will lose its ${ }^{3} \mathrm{H}$, i.e. $\left[5-{ }^{3} \mathrm{H}\right] \mathrm{G} 6 \mathrm{P}+\mathrm{GAP} \leftrightarrow \mathrm{F} 6 \mathrm{P}+\left[2-{ }^{3} \mathrm{H}\right] \mathrm{GAP}$. The ${ }^{3} \mathrm{H}$ of the $\left[2-{ }^{3} \mathrm{H}\right] \mathrm{GAP}$ will be lost to water in its isomerisation with DHAP. The conversion of this F6P to glycogen will then result in underestimation of the direct pathway's contribution. Assuming no difference in rates because of the different isotopes, i.e. ${ }^{2} \mathrm{H}$ and ${ }^{3} \mathrm{H}$, the underestimation of the direct pathway contribution should equal the overestimation of the indirect pathway contribution. As a result, the sum of their contributions should then be unaffected by the exchange.

In conclusion, during postprandial conditions the combined measurement of the direct and indirect pathways allows measurement of glycogen cycling. Glycogen cycling occurs most in the early hours upon glucose loading following a fast.

Acknowledgements These studies were supported by grants from the Austrian National Bank (9127) to H. Stingl and M. Roden, the National Institutes of Health (RO1-DK-14507) to B. R. Landau, the Austrian Science Foundation (FWF; P15656), the European Foundation for the Study of Diabetes (EFSD and Novo-Nordisk Type 2 Program Focused Research grant), the Herzfelder'sche Family Trust to M. Roden and by an Institutional grant of Novo-Nordisk to W. Waldhäusl. We thank Georg Pfeiler and the team of the laboratory of the Division of Endocrinology and Metabolism, University of Vienna, for technical assistance.

\section{References}

1. Landau BR (2001) Methods for measuring glycogen cycling. Am J Physiol Endocrinol Metab 281:E413-E419

2. Magnusson I, Rothman DL, Jucker B, Cline GW, Shulman RG, Shulman GI (1994) Liver glycogen turnover in fed and fasted humans. Am J Physiol Endocrinol Metab 266:E796-E803

3. Magnusson I, Rothman DL, Katz LD, Shulman RG, Shulman GI (1992) Increased rate of gluconeogenesis in type II diabetes mellitus. A ${ }^{13} \mathrm{C}$ nuclear magnetic resonance study. J Clin Invest 90:1323-1327

4. Hundal RS, Krssak M, Dufour S et al (2000) Mechanism by which metformin reduces glucose production in type 2 diabetes. Diabetes 49:2063-2069

5. Boden G, Chen X, Stein TP (2001) Gluconeogenesis in moderately and severely hyperglycemic patients with type 2 diabetes mellitus. Am J Physiol Endocrinol Metab 280:E23E30

6. Krebs HA (1963) Renal gluconeogenesis. Adv Enzyme Regul $17: 385-400$

7. Exton JH (1987) Mechanisms of hormonal regulation of hepatic glucose metabolism. Diabetes Metab Rev 3:163-183

8. Landau BR (1999) Quantifying the contribution of gluconeogenesis to glucose production in fasted human subjects using stable isotopes. Proc Nutr Soc 58:963-972 
9. Landau BR, Wahren J, Chandramouli V, Schumann WC, Ekberg K, Kalhan SC (1995) Use of ${ }^{2} \mathrm{H}_{2} \mathrm{O}$ for estimating rates of gluconeogenesis. Application to the fasted state. J Clin Invest 95:172-178

10. Landau BR, Wahren J, Chandramouli V, Schumann WC, Ekberg K, Kalhan SC (1996) Contributions of gluconeogenesis to glucose production in the fasted state. J Clin Invest 98:378385

11. Rothman DL, Magnusson I, Katz LD, Shulman RG, Shulman GI (1991) Quantitation of hepatic glycogenolysis and gluconeogenesis in fasting humans with ${ }^{13} \mathrm{C}$ NMR. Science 254 : 573-576

12. Rossetti L, Giaccari A, Barzilai N, Howard K, Sebel G, Hu M (1993) Mechanism by which hyperglycemia inhibits hepatic glucose production in conscious rats. Implications for the pathophysiology of fasting hyperglycemia in diabetes. J Clin Invest 92:1126-1134

13. Hellerstein MK, Neese RA, Schwarz JM, Turner S, Faix D, Wu K (1997) Altered fluxes responsible for reduced hepatic glucose production and gluconeogenesis by exogenous glucose in rats. Am J Physiol Endocrinol Metab 272:E163-E172

14. Hellerstein MK, Neese RA, Linfoot P, Christiansen M, Turner S, Letscher A (1997) Hepatic gluconeogenic fluxes and glycogen turnover during fasting in humans. A stable isotope study. J Clin Invest 100:1305-1319

15. Petersen KF, Laurent D, Rothman DL, Cline GW, Shulman GI (1998) Mechanism by which glucose and insulin inhibit net hepatic glycogenolysis in humans. J Clin Invest 101:12031209

16. Roden M, Stingl H, Chandramouli V et al (2000) Effects of free fatty acid elevation on postabsorptive endogenous glucose production and gluconeogenesis in humans. Diabetes 49:701707

17. Stingl H, Krssak M, Krebs M et al (2001) Lipid-dependent control of hepatic glycogen stores in healthy humans. Diabetologia 44:48-54

18. Petersen KF, Krssak M, Navarro V et al (1999) Contributions of net hepatic glycogenolysis and gluconeogenesis to glucose production in cirrhosis. Am J Physiol Endocrinol Metab 276: E529-E535

19. Exton JH, Corbin JG, Park CR (1969) Control of gluconeogenesis in liver: IV. Differential effects of fatty acids and glucagon on ketogenesis and gluconeogenesis in the perfused rat liver. J Biol Chem 244:4095-4102

20. Shulman GI, Landau BR (1992) Pathways of glycogen repletion. Physiol Rev 72:1019-1035

21. Radziuk J (1989) Hepatic glycogen in humans: I. Direct formation after oral and intravenous glucose or after a 24-h fast. Am J Physiol 257:E145E-E157

22. Radziuk J (1989) Hepatic glycogen in humans: II. Gluconeogenetic formation after oral and intravenous glucose. Am J Physiol Endocrinol Metab 257:E158-E169

23. Roden M (1997) NMR and stable isotope techniques for studies of liver metabolism in man. Horm Metab Res 29:340-343

24. Wajngot A, Chandramouli V, Schumann WC, Efendic S, Landau BR (1991) Quantitation of glycogen/glucose-1-P cycling in liver. Metabolism 40:877-881

25. Magnusson I, Chandramouli V, Schumann WC, Kumaran K, Wahren J, Landau BR (1987) Quantitation of the pathways of hepatic glycogen formation on ingesting a glucose load. J Clin Invest 80:1748-1754

26. Kunert O, Stingl H, Rosian E et al (2003) Measurement of fractional whole-body gluconeogenesis in humans from blood samples using ${ }^{2} \mathrm{H}$ nuclear magnetic resonance spectroscopy. Diabetes 52:2475-2482

27. Inzucchi SE, Maggs DG, Spollett GR et al (1998) Efficacy and metabolic effects of metformin and troglitazone in type II diabetes mellitus. N Engl J Med 338:867-872
28. Hother-Nielsen O, Mengel A, Moller J, Rasmussen O, SchmitzO, Beck-Nielsen H (1992) Assessment of glucose turnover rates in euglycaemic clamp studies using primed-constant $\left[3-{ }^{3} \mathrm{H}\right]-$ glucose infusion and labelled or unlabelled glucose infusates. Diabet Med 9:840-849

29. Chandramouli V, Ekberg K, Schumann WC, Wahren J, Landau BR (1999) Origins of the hydrogen bound to carbon 1 of glucose in fasting: significance in gluconeogenesis quantitation. Am J Physiol Endocrinol Metab 277:E717-723

30. Yang D, Diraison F, Beylot M, et al (1998) Assay of low deuterium enrichment of water by isotopic exchange with $\left[\mathrm{U}-{ }^{13} \mathrm{C} 3\right]$ acetone and gas chromatography-mass spectrometry. Anal Biochem 258:315-321

31. Previs SF, Fatica R, Chandramouli V, Alexander JC, Brunengraber H, Landau BR (2004) Quantifying rates of protein synthesis in humans by use of ${ }^{2} \mathrm{H}_{2} \mathrm{O}$ : application to patients with end-stage renal disease. Am J Physiol Endocrinol Metab 286:E665-E672

32. Magnusson I, Chandramouli V, Schumann WC, Kumaran K, Wahren J, Landau BR (1988) Pentose pathway in human liver. Proc Natl Acad Sci U S A 85:4682-4685

33. Musson DG, Lin JH, Lyon KA, Tocco DJ, Yeh KC (1985) Assay methodology for quantification of the ester and ether glucuronide conjugates of diflunisal in human urine. J Chromatogr 337:363378

34. Jung D, Zafar NU (1985) Micro high-performance liquid chromatographic assay of acetaminophen and its major metabolites in plasma and urine. J Chromatogr 339:198-202

35. Dische Z, Rothschild C (1967) Two modifications of the carbazole reaction of hexuronic acids for the differentiation of polyuronides. Anal Biochem 21:125-130

36. Partridge SM (1948) Filter-paper partition chromatography of sugars. Biochem J 42:238-250

37. Schumann WC, Gastaldelli A, Chandramouli V et al (2001) Determination of the enrichment of the hydrogen bound to carbon 5 of glucose on ${ }^{2} \mathrm{H}_{2} \mathrm{O}$ administration. Anal Biochem 297:195-197

38. Steele R (1959) Influences of glucose loading and of injected insulin on hepatic glucose output. Ann NY Acad Sci 82:420 430

39. Hellerstein MK, Greenblatt DJ, Munro HN (1987) Glycoconjugates as noninvasive probes of intrahepatic metabolism: I. Kinetics of label incorporation with evidence of a common precursor UDP-glucose pool for secreted glycoconjugates. Metabolism 36:988-994

40. Landau BR, Wahren J (1988) Quantification of the pathways followed in hepatic glycogen formation from glucose. FASEB J 2:2368-2375

41. Shulman GI, Cline G, Schumann WC, Chandramouli V, Kumaran K, Landau BR (1990) Quantitative comparison of pathways of hepatic glycogen repletion in fed and fasted humans. Am J Physiol Endocrinol Metab 259:E335-E341

42. Petersen KF, Cline GW, Gerard DP, Magnusson I, Rothman DL, Shulman GI (2001) Contribution of net hepatic glycogen synthesis to disposal of an oral glucose load in humans. Metabolism 50:598-601

43. Butler PC, Rizza RA (1991) Contribution to postprandial hyperglycemia and effect on initial splanchnic glucose clearance of hepatic glucose cycling in glucose-intolerant or NIDDM patients. Diabetes 40:73-81

44. Pagliassotti MJ, Cherrington AD (1992) Regulation of net hepatic glucose uptake in vivo. Annu Rev Physiol 54:847-860

45. Exton JH, Park CR (1968) Control of gluconeogenesis in liver: II. Effects of glucagon, catecholamines, and adenosine 3',5'-monophosphate on gluconeogenesis in the perfused rat liver. J Biol Chem 243:4189-4196

46. Roden M, Perseghin G, Petersen KF et al (1996) The roles of insulin and glucagon in the regulation of hepatic glycogen synthesis and turnover in humans. J Clin Invest 97:642-648 
47. Adkins A, Basu R, Persson M et al (2003) Higher insulin concentrations are required to suppress gluconeogenesis than glycogenolysis in nondiabetic humans. Diabetes 52:2213-2220

48. Cherrington AD, Williams PE, Shulman GI, Lacy WW (1981) Differential time course of glucagon's effect on glycogenolysis and gluconeogenesis in the conscious dog. Diabetes 30:180187

49. Exton JH, Park CR (1967) Control of gluconeogenesis in liver: I. General features of gluconeogenesis in the perfused livers of rats. J Biol Chem 242:2622-2636

50. Villar-Palasi C, Larner J (1960) Levels of activity of the enzymes of the glycogen cycle in rat tissues. Arch Biochem Biophys 86:270-273

51. Scrutton MC, Utter MF (1968) The regulation of glycolysis and gluconeogenesis in animal tissues. Annu Rev Biochem 37:249-302
52. El-Refai M, Bergman RN (1976) Simulation study of control of hepatic glycogen synthesis by glucose and insulin. Am J Physiol 231:1608-1619

53. Chandramouli V, Ekberg K, Schumann WC, Kalhan SC, Wahren J, Landau BR (1997) Quantifying gluconeogenesis during fasting. Am J Physiol Endocrinol Metab 273:E1209E1215

54. Ljungdahl L, Wood HG, Racker E, Couri D (1961) Formation of unequally labeled fructose 6-phosphate by an exchange reaction catalyzed by transaldolase. J Biol Chem 236:1622-1625

55. Landau BR, Bartsch GE (1966) Estimations of pathway contributions to glucose metabolism and the transaldolase reactions. J Biol Chem 241:741-749 